\title{
Experimental Investigation and Modeling of Activity Coefficient at Infinite Dilution of Solutes Using Dicationic Solvent Based on Pyrrolidinium as a New Stationary Phase in Gas Chromatography
}

\author{
Ali Yahyaee ${ }^{*}$, Mina Nazifi², Mohsen Kianpour ${ }^{3}$, Kurosh Tabar Heidar² \\ ${ }^{1}$ School of Mechanical Engineering, Iran University of Science and Technology (IUST), Tehran, Iran \\ ${ }^{2}$ Chemistry and Chemical Engineering Research Center of Iran, Tehran, Iran \\ ${ }^{3}$ Iranian Catalyst Development (ICD), Tehran, Iran \\ Email: *Alidyahyaee@gmail.com
}

How to cite this paper: Yahyaee, A., Nazifi, M., Kianpour, M. and Heidar, K.T. (2018) Experimental Investigation and Modeling of Activity Coefficient at Infinite Dilution of Solutes Using Dicationic Solvent Based on Pyrrolidinium as a New Stationary Phase in Gas Chromatography. American Journal of Analytical Chemistry, 9, 257-271.

https://doi.org/10.4236/ajac.2018.94020

Received: January 22, 2018

Accepted: April 23, 2018

Published: April 26, 2018

Copyright (c) 2018 by authors and Scientific Research Publishing Inc. This work is licensed under the Creative Commons Attribution International License (CC BY 4.0).

http://creativecommons.org/licenses/by/4.0/

\begin{abstract}
Activity coefficients at infinite dilution, $\gamma \infty i$, were calculated for 12 solutes, with organic solutes including linear alcohols (methanol, ethanol, propanol), linear alkanes (heptane, octane), benzene, toluene, cyclohexane, 1, 2-dichloroethane, trichloroethylene, acetonitrile and carbon tetrachloride. The values of $\gamma \infty i$ were determined via either thermodynamic or artificial neural network modelling at different temperatures. A comparison between extracted results from these two methods confirmed that experimental and predicted results are roughly the same. The accuracy of predicted results proves this model is fully compatible with a wide range of solutes, and it can readily be used as an alternative to conventional gas-liquid chromatography for the measurements of activity coefficient at infinite dilution.
\end{abstract}

\section{Keywords}

Gas Chromatography, Ionic Liquid, Activity Coefficients at Infinite Dilution, Artificial Neural Network (ANN), Thermodynamic Modeling

\section{Introduction}

The measurements of activity coefficient at infinite dilution ( $\left.\gamma_{\infty}\right)$ are crucially important for either theoretical or practicing chemistry. This parameter describes the behavior of a solute completely surrounded by solvent molecules. Ac- 
tivity coefficients at infinite dilution have been widely used for determining quantity of solutes' volatility and also made information about intermolecular energy between solvent and solute [1] [2] [3] [4] [5]. Values of yoo are decisive factors for the calculation of limiting separation factors necessary for the reliable design of distillation processes and the selection of solvents for extraction and extractive distillation. Moreover, activity coefficients are important for characterizing the behavior of liquid mixtures, predicting the existence of azeotrope, estimation of mutual solubility and calculation of Henry constants and partition coefficients.

Several methods were developed for the measurement of yos such as dilutor technique (DT) [6] [7], inert gas stripping [6], differential ebulliometry [8], head space [9] and dew point techniques [10]. However, there are some drawbacks, in terms of time, cost and material, associated with each method. As chromatographic technique needs less than 1 gram of ILs and it can be considered as a cost-efficient, rapid and reliable method.

It is important to have a simple method to estimate all property distributions from known bulk properties. Artificial Neural Networks (ANN) has been widely applied to an extensive range of chemical engineering such as process modeling, optimization and PVT behavior over the last 20 years. In the mathematical algorithm of ANN, it is possible to relate input and output parameters without requiring prior knowledge of relationships between the process parameters [11] [12] [13] [14] [15].

In this work, values of $\gamma_{\infty}$ (the activity coefficients at infinite dilution) for 12 compounds in the following di-cationic ionic liquid with three phase loadings $(10 \%, 15 \%$ and $20 \%)$ have been determined at various temperatures 308,313 , 318 and $323 \mathrm{~K}$. Regarding the importance of activity coefficient at infinite dilution in thermodynamic and separation processes, a growing need for gaining activity coefficient in a simple and fast way has been felt. Therefore, an artificial neural network (ANN) model has been developed to predict the measures of $\gamma_{\infty}$ for an extensive range of solutes.

\section{Experimental}

\subsection{Solvents and Solutes}

All solvents were distilled from standard drying agents before use. All used Ionic Liquids were synthesized in CCERI [1]. N-Methyl pyrrolidine, 1, 9-di-bromononane, Lithium bis (trifluoromethylsulfonyl) imide and pentaoxide phosphor were purchased from Sigma-Aldrich company. $1 \mathrm{H} \mathrm{NMR} \mathrm{spectra} \mathrm{(500} \mathrm{MHz})$ were recorded in deuterated ACN. Since the GLC process separated the solutes from any impurities, the solutes were used without further purification.

Structures of di-cationic ionic liquids $\mathrm{C}_{12}(\mathrm{mPy})_{2}\left(\mathrm{NTf}_{2}\right)_{2}$ is shown in Figure 1.

All solutes including linear alcohols (methanol, ethanol, propanol), linear alkanes (heptane, octane), benzene, toluene, cyclohexane, 1, 2-dichloroethane, trichloroethylene, acetonitrile and carbon tetra chloride, were supplied from MERCK. 


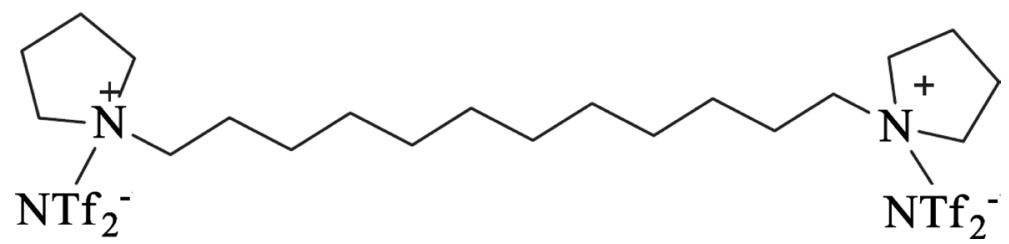

Figure 1. Structures of di-cationic ionic liquids $\mathrm{C}_{12}\left(\mathrm{mPy}_{2}\left(\mathrm{NTf}_{2}\right)_{2}\right.$.

\subsection{Analysis Method}

Gas chromatography experiments were performed using a Varian CP-3800 gas chromatograph equipped with a heated 1041 injector and a thermal conductivity detector (TCD). The injector and detector temperatures were kept constant at $473 \mathrm{~K}$ during all experiments. The flow rate of helium was adjusted to obtain adequate retention times. The dead time was determined by injection of air with each solute. A personal computer equipped software as used for recording detector signals and corresponding chromatograms were obtained by Galaxie software.

\subsection{Stationary Phase Preparation and Sample Injection Condition}

Column packing, containing from $10 \%, 15 \%$ and $20 \%$ of stationary phase (IL) on Chromosorb W-AW (80 - $100 \mathrm{mesh}$ ), was prepared using the rotary evaporator technique. After evaporation of the dichloromethane under vacuum, the support was equilibrated at $323 \mathrm{~K}$ for 18 hours. The solid support material with the stationary phase was filled in a stainless steel column with an inner diameter of $3 \mathrm{~mm}$ and a length of $1 \mathrm{~m}$. The weight of the packing material was calculated from the weights of the packed and empty column. A volume of the headspace vapor of samples of $0.1-0.5$ micro liter was introduced to be in infinite dilution conditions. No differences in retention times $t_{r}$ were found by injecting individual pure components or their mixtures. The measurements were carried out at temperatures between 308 and $323 \mathrm{~K}$. At a given temperature, each experiment was repeated at least three times to verify the reproducibility. The difference of the retention times of the three measurements was ordinarily reproducible within (0.01 to 0.1$) \mathrm{min}$.

Under aforementioned condition, the retention data for 12 solutes in 3 gas-chromatography columns with different phase load (10\%, 15\%, and 20\%) and in different temperature $(308,313$, and $318 \mathrm{~K})$ have been obtained and used for calculating of activity coefficients at infinite dilution.

\section{Modeling}

\subsection{Thermodynamic Modeling}

Equation (1) suggested by Everett and Cruickshank et al. [16] [17] shown below, was used for determining of $\gamma_{i}^{\infty}$ values for the solute eluting in a carrier gas.

$$
\operatorname{Ln} \gamma_{i}^{\infty}=\operatorname{Ln}\left(\frac{n R T}{V^{n} P^{s}}\right)-P^{s} \frac{B^{11}-V^{s}}{R T}+\frac{2 B^{12}-V_{\infty}}{R T} J P^{o}
$$


where $n$ is the mole number of the stationary phase component inside the column, $R$ is the ideal gas constant, $T$ is the temperature of the oven, $V^{N}$ is the standardized retention volume of the solute, $P^{\circ}$ is the column outlet pressure (equal to atmospheric pressure), $V^{\delta}$ the saturated liquid molar volume of the solute at $T$ and $V^{\infty}$ is the partial molar volume of the solute at infinite dilution in the solvent. $B^{11}$ the second Virial coefficient of the solute in the gaseous state at temperature $T, B^{12}$ the mutual Virial coefficient between the solute 1 and the carrier gas helium 2 and $P^{S}$ is the probe vapor pressure at temperature $T$. The second and third terms in Equation (1) are correction terms that result from the non-ideality of the mobile gaseous phase. The molar volume of the solute $V^{\delta}$ was determined from experimental densities, and the partial molar volumes of the solutes at infinite dilution $V^{\infty}$ were assumed to be equal to $V^{\delta}$. The vapor pressure values were calculated using the Antoine equation [18] [19]. The standardized retention volume, $V^{N}$, can be calculated with the following relationship:

$$
V_{N}=J U_{o} t_{r}^{\prime}
$$

The adjusted retention time, $t_{r}^{\prime}$ calculated from the difference between the retention times of a solute and that of air. $U_{0}$, the flow rate of the carrier gas, measured at the room temperature. The factor $J$ corrects for the influence of the pressure drop along the column. Among of J relies on the pressure at the column outlet and inlet. This factor is defined by Equation (3).

$$
J=\frac{3}{2} \frac{\left(p_{i}-p_{o}\right)^{2}-1}{\left(p_{i}-p_{o}\right)^{3}-1}
$$

The values of $B^{11}$ and $B^{12}$ were calculated using the McGlashan and Potter [20].

The critical properties of the pure component $\left(T_{c}^{11}\right.$ and $\left.V_{c}^{11}\right)$ was extracted from the literature [21] [22] and the mutual critical data $T_{c}^{12}, V_{c}^{12}$ were calculated using the combining rule presented by Hudson and McCoubrey [23].

Activity coefficients at infinite dilution of various types of solutes were computed in the di-cationic stationary phase with different phase load (10\%, 15\%, and $20 \%$ ) in four temperatures $(308,313,318$, and $323 \mathrm{~K})$. The obtained results of activity coefficients at infinite dilution for 12 solutes are presented in Table 1.

\subsection{Artificial Intelligent Modeling}

An artificial neural network was applied to model the system in order to predict activity coefficient of dilute solution for lots of chemical compounds. 144 data sets were used for training and testing. 70\% of these data have been used for training, test data and validate data used the equal percentage of 15.

One of the most popular and commonly used networks is the multilayer perceptron network (MLP). The MLP configuration has gained a widespread use in static regression applications [24]-[29]. It can have one or more hidden layer(s).Whereas Cybenko [30] and Huang et al. [31] had proved that a one hidden layer network is suitable to represent any type of multidimensional 
A. Yahyaee et al.

Table 1. Activity coefficient of solutes at infinite dilute solution.

\begin{tabular}{|c|c|c|c|c|}
\hline Solutes & $\mathrm{T} / \mathrm{K}$ & 10 & 15 & 20 \\
\hline \multirow[t]{4}{*}{ Benzene } & 308 & 0.2653 & 0.3249 & 0.2644 \\
\hline & 313 & 0.2778 & 0.3322 & 0.2597 \\
\hline & 318 & 0.2751 & 0.4048 & 0.2744 \\
\hline & 323 & 0.3020 & 0.4219 & 0.3101 \\
\hline \multirow[t]{4}{*}{ Methanol } & 308 & 0.3905 & 0.4311 & 0.4185 \\
\hline & 313 & 0.3656 & 0.4528 & 0.3859 \\
\hline & 318 & 0.3571 & 0.4696 & 0.4092 \\
\hline & 323 & 0.4426 & 0.5885 & 0.4454 \\
\hline \multirow[t]{4}{*}{ Ethanol } & 308 & 0.4968 & 0.5988 & 0.5385 \\
\hline & 313 & 0.4626 & 0.5990 & 0.4967 \\
\hline & 318 & 0.4373 & 0.6220 & 0.5130 \\
\hline & 323 & 0.5625 & 0.7060 & 0.5372 \\
\hline \multirow[t]{4}{*}{ Propanol } & 308 & 0.6000 & 0.7150 & 0.6612 \\
\hline & 313 & 0.6142 & 0.7967 & 0.6564 \\
\hline & 318 & 0.5975 & 0.6890 & 0.6201 \\
\hline & 323 & 0.6716 & 0.8444 & 0.6473 \\
\hline \multirow[t]{4}{*}{ Acetonitrile } & 308 & 0.1529 & 0.1838 & 0.1596 \\
\hline & 313 & 0.1594 & 0.1968 & 0.1565 \\
\hline & 318 & 0.1620 & 0.2021 & 0.1591 \\
\hline & 323 & 0.1991 & 0.2310 & 0.1796 \\
\hline \multirow[t]{4}{*}{ Cyclohexane } & 308 & 2.4003 & 2.6037 & 2.3272 \\
\hline & 313 & 2.3132 & 2.7101 & 2.2169 \\
\hline & 318 & 2.2900 & 2.7948 & 2.2222 \\
\hline & 323 & 2.3168 & 3.9487 & 2.4903 \\
\hline \multirow[t]{4}{*}{ Toluene } & 308 & 0.3538 & 0.4473 & 0.3446 \\
\hline & 313 & 0.3732 & 0.4436 & 0.3468 \\
\hline & 318 & 0.3726 & 0.4538 & 0.3705 \\
\hline & 323 & 0.3753 & 0.4306 & 0.4171 \\
\hline \multirow[t]{4}{*}{ Heptane } & 308 & 4.5788 & 5.5034 & 5.0667 \\
\hline & 313 & 5.3570 & 5.5809 & 4.7640 \\
\hline & 318 & 4.6549 & 5.5048 & 4.8457 \\
\hline & 323 & 5.7666 & 5.8925 & 5.6490 \\
\hline \multirow[t]{4}{*}{ Octane } & 308 & 7.0796 & 7.9705 & 7.6836 \\
\hline & 313 & 5.9958 & 7.4999 & 6.6670 \\
\hline & 318 & 5.7462 & 7.3969 & 6.8222 \\
\hline & 323 & 6.3740 & 9.2261 & 9.1810 \\
\hline \multirow[t]{4}{*}{ Dichloroethane } & 308 & 0.1622 & 0.2034 & 0.1712 \\
\hline & 313 & 0.2052 & 0.2481 & 0.1670 \\
\hline & 318 & 0.2362 & 0.2919 & 0.1976 \\
\hline & 323 & 0.3322 & 0.4202 & 0.2465 \\
\hline Carbontetrachloride & 308 & 0.4863 & 0.5602 & 0.4735 \\
\hline
\end{tabular}




\begin{tabular}{lllll} 
Continued & \multicolumn{5}{l}{} \\
\hline \multirow{3}{*}{ Trichloroethylene } & 313 & 0.5864 & 0.6787 & 0.4642 \\
& 318 & 0.7309 & 0.8205 & 0.5208 \\
& 323 & 0.8610 & 1.1592 & 0.6568 \\
& 308 & 0.2722 & 0.3176 & 0.2680 \\
& 313 & 0.3210 & 0.3880 & 0.2615 \\
& 318 & 0.3823 & 0.4747 & 0.2560 \\
& 323 & 0.5137 & 0.6638 & 0.3002 \\
\hline
\end{tabular}

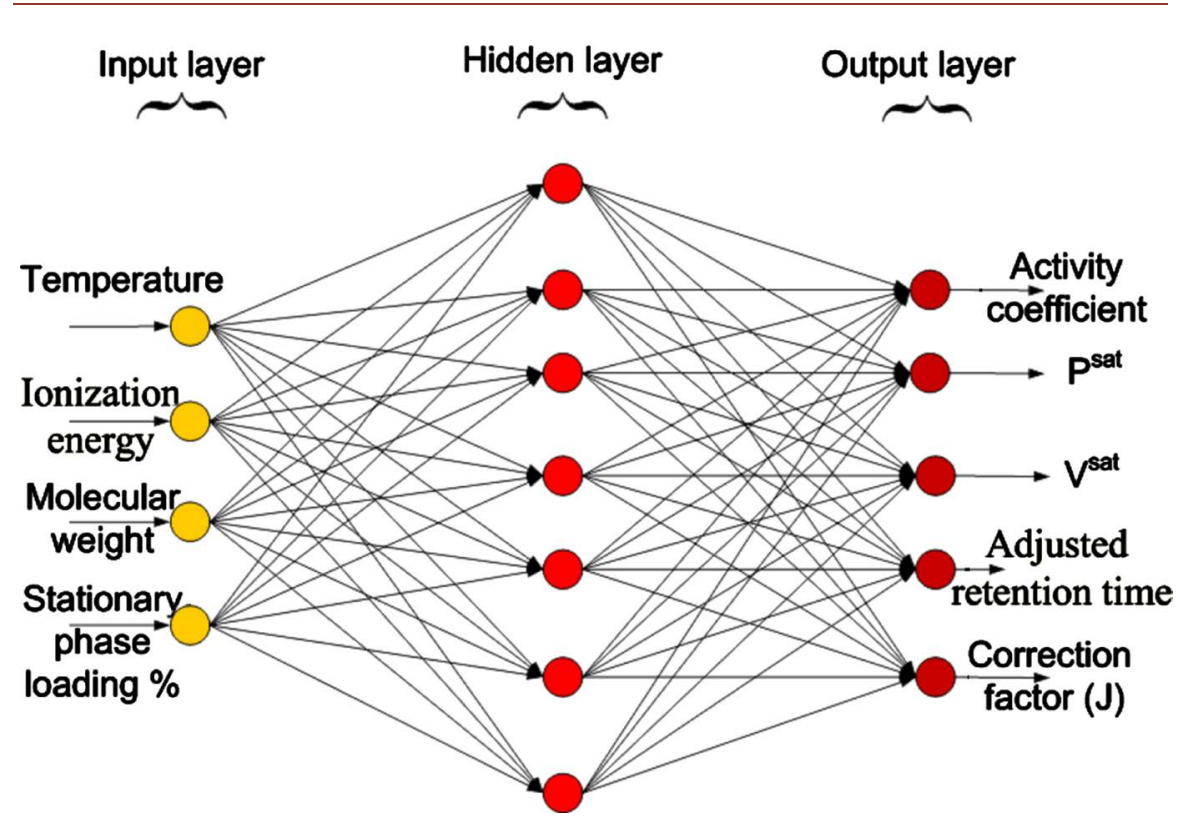

Figure 2. The selected structure for the artificial neural network (Ann).

non-linear function with sufficient number of neurons and more hidden layers may result in over-fitting, therefore, in this work, one hidden layer was applied as displayed in Figure 2. In addition, a procedure modified at our last works [32] [33] was selected to design a relatively small and entirely accurate network. The procedure flowchart is shown in Figure 3. At the first step of the procedure, a training method was randomly applied to find the number of neurons in the hidden layer that minimizes the mean squared normalized error (MSE) (defined by Equation (4)) of the network.

$$
\operatorname{MSE}=\frac{1}{N} \sum_{i=1}^{N} e_{i}^{2}
$$

where $e_{i}$ is the differences between experimental and predicted data.

In order to improve the model generalization and prevent over-fitting, the number of neurons has to be chosen so that the number of internal parameters in the network does not exceed the number of training data sets [34]. The number of internal parameters was calculated according to the following equation [35]:

$$
n_{\text {tot }}=\left(n_{i}+1\right) \times n_{h 1}+\left(n_{h 1}+1\right) \times n_{h 2}+\cdots+\left(n_{h n}+1\right) \times n_{o}
$$




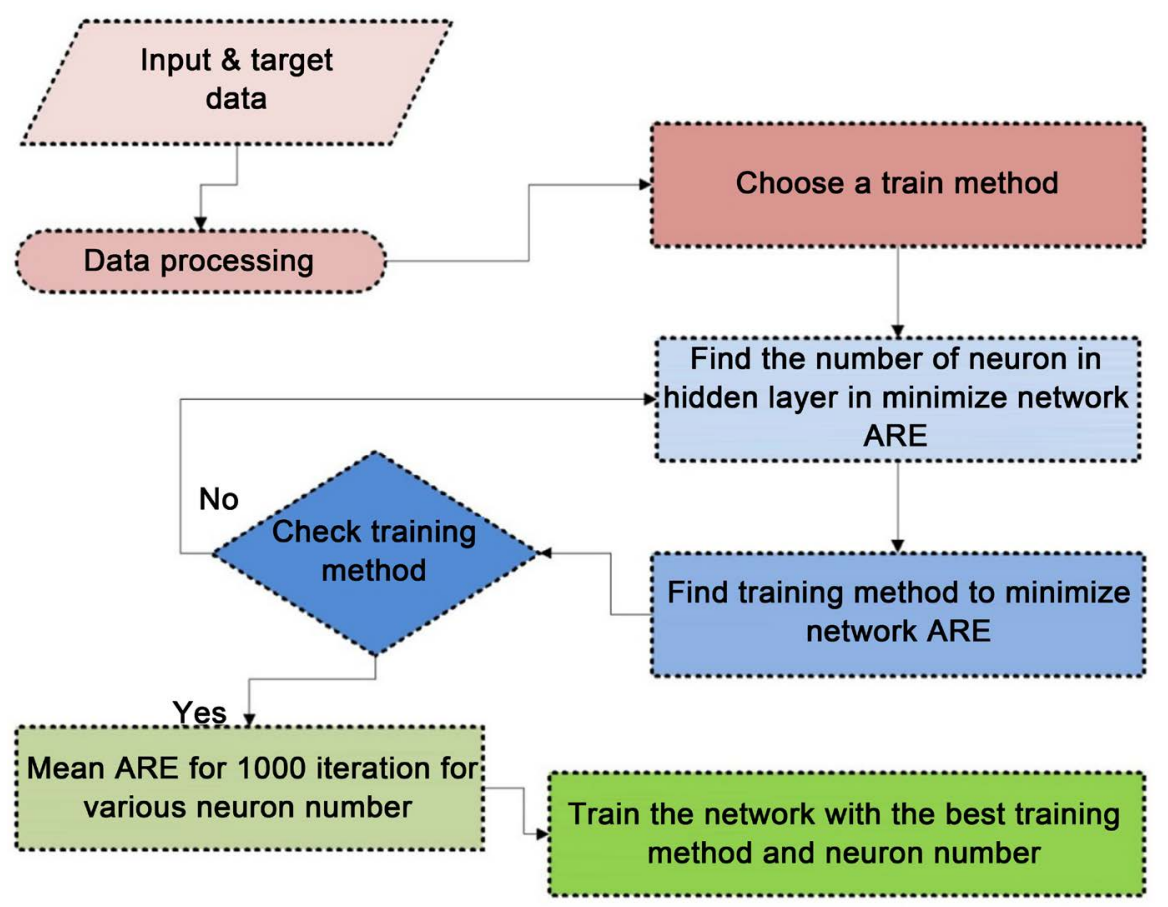

Figure 3. The procedure to design artificial neural network.

where, $n_{\text {tot }}$ is the total number of network parameters, $n_{o}$ is the number of outputs and $n_{h i}$ is the number of the neurons in the th hidden layer. In this work, the maximum number of neurons that can be used in hidden layer in this system to prevent over-fitting was calculated to be seven. Thus, the choice of neuron number was limited in the range of $1-7$ neurons for the hidden layer. At the second step, the network with the neuron number of the last step was used to find a training method that leads to minimum MSE of the network. If the network MSE was less than the desirable MSE the third step was started. Otherwise, the last two steps were repeated till the desirable MSE value was reached.

The applied training methods consist of Bayesian Regularization (BR), BFGS ${ }^{1}$ Quasi-Newton (BFG), Resilient Backpropagation (RP), Scaled Conjugate Gradient (SCG), Conjugate Gradient with Powell/Beale Restarts (CGB), Levenberg-Marquardt (LM), Fletcher-Powell Conjugate Gradient (CGF), Polak-Ribiére Conjugate Gradient (CGP), One Step Secant (OSS), Variable Learning Rate Gradient Descent (GDX), Gradient Descent with Momentum (GDM), and Gradient Descent (GD).

At the third step, the selected training method was applied to train the network using a number of neurons $(1-8)$. Each of these trainings was repeated 1000 time and the means of MSEs for the repeated trainings were recorded.

In addition to MSE, correlation coefficients $(R)$ are commonly used to verify ANN models. In this work $R$ has also been applied as defined by Equation (6).

$$
R=\frac{\sum\left(\alpha_{i}-\bar{\alpha}\right)\left(\tau_{i}-\bar{\tau}\right)}{\sqrt{\sum\left(\alpha_{i}-\bar{\alpha}\right)^{2} \sum\left(\tau_{i}-\bar{\tau}\right)^{2}}}
$$

${ }^{1}$ Hesian updating methods of Broyden, Fletcher, Goldfarb, Shanno (BFGS). 
where, $\tau_{i}$ is the target and $\alpha_{i}$ is the network output and $\bar{\tau}, \bar{\alpha}$ are the mean amount of the data.

\section{Results}

The ANN model was also employed to predict activity coefficient at infinite dilution of different solutes. The procedure described in section 3 was applied to design the model. Temperature, Ionization energy, Molecular weight and stationary phase loading were chosen as the input data of network and Activity coefficient, Saturated pressure, Saturated volume, Adjusted retention time and the correction factor ( $/$ ) were chosen as the output data.

Levenberg-Marquardt (LM) method was found to have the minimum error as shown in Table 2. Mean squared normalized error of the ANN model is indicated in Figure 4. This figure shows that using seven neurons has resulted in a minimum error. Therefore, this structure (144:7:1) was selected as the best network to model this system. Hence, a network with seven neurons in the hidden layer which trained by Levenberg-Marquardt (LM) method, selected as the best network. Optimal network structure can be seen in Figure 2. This network consists of 144 input data that divided to train, test and validation data.

The results of ANN model and experimental data are depicted in Figure 5 and Figure 6. Figure 5, the regression plot of the ANN model and experimental data, shows an accurate prediction for the model. The error histogram with twenty

Table 2. The results of different training methods; Mean squared normalized error of the data.

\begin{tabular}{|c|c|c|c|c|}
\hline & Overall data & Train data & Validate data & Test data \\
\hline Trainb & 1714.857 & 1752.72 & 1070.62 & 2186.99 \\
\hline trainbfg & 63.4526 & 50.5515 & 63.4818 & 122.065 \\
\hline Trainbr & 16.33893 & 16.3389 & 1450277 & 2450.28 \\
\hline Trainc & 572.8554 & 571.264 & 793.043 & 359.9 \\
\hline traincgb & 297.3109 & 277.746 & 368.5 & 315.055 \\
\hline traincgf & 283.4068 & 276.4 & 279.52 & 319.142 \\
\hline traincgp & 270.6267 & 213.914 & 391.736 & 407.301 \\
\hline Traingd & 270.6267 & 261.347 & 350.299 & 233.134 \\
\hline traingda & 270.6267 & 266.085 & 159.743 & 402.153 \\
\hline traingdm & 270.6267 & 298.904 & 215.837 & 196.885 \\
\hline Traingd & 270.6267 & 282.871 & 165.608 & 319.99 \\
\hline Trainlm & 0.111587 & 0.08726 & 0.16761 & 0.16613 \\
\hline trainoss & 26.00845 & 28.9234 & 25.3603 & 13.4069 \\
\hline Trainr & 162.3016 & 177.837 & 172.875 & 81.1113 \\
\hline Trainrp & 80.94391 & 87.1408 & 73.3158 & 60.4043 \\
\hline Trains & 71.17467 & 74.2786 & 65.688 & 62.5527 \\
\hline trainscg & 71.17467 & 76.5718 & 54.7914 & 63.0255 \\
\hline
\end{tabular}




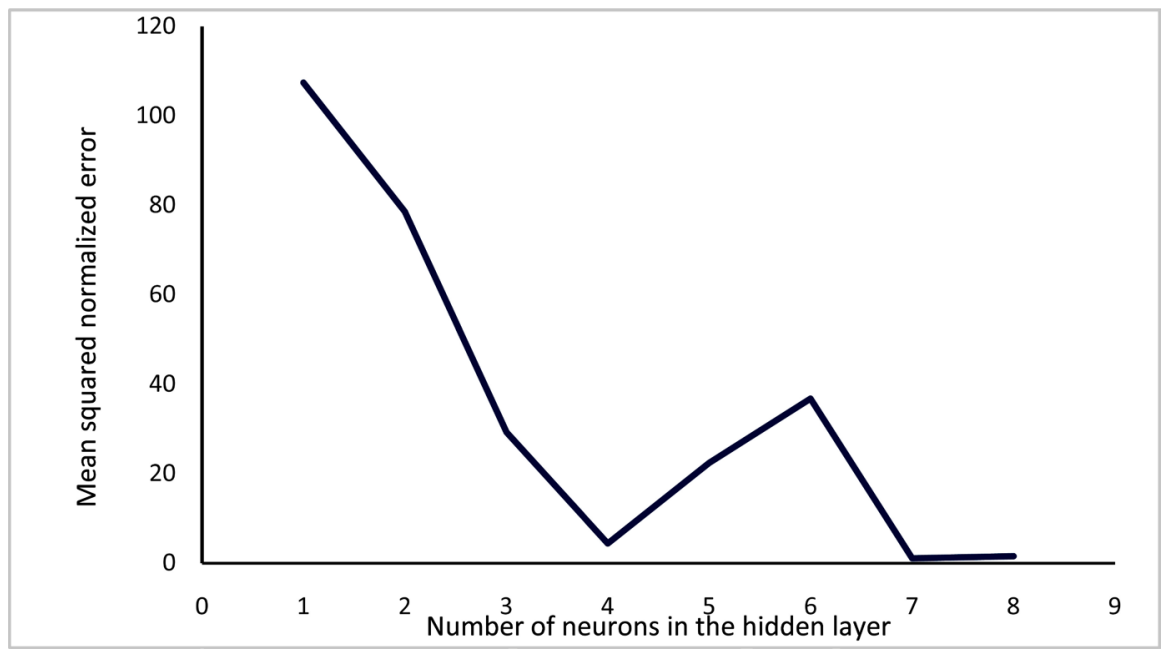

Figure 4. The variation of average relative error and $\mathrm{R}$ with number of neurons in the hidden layer.

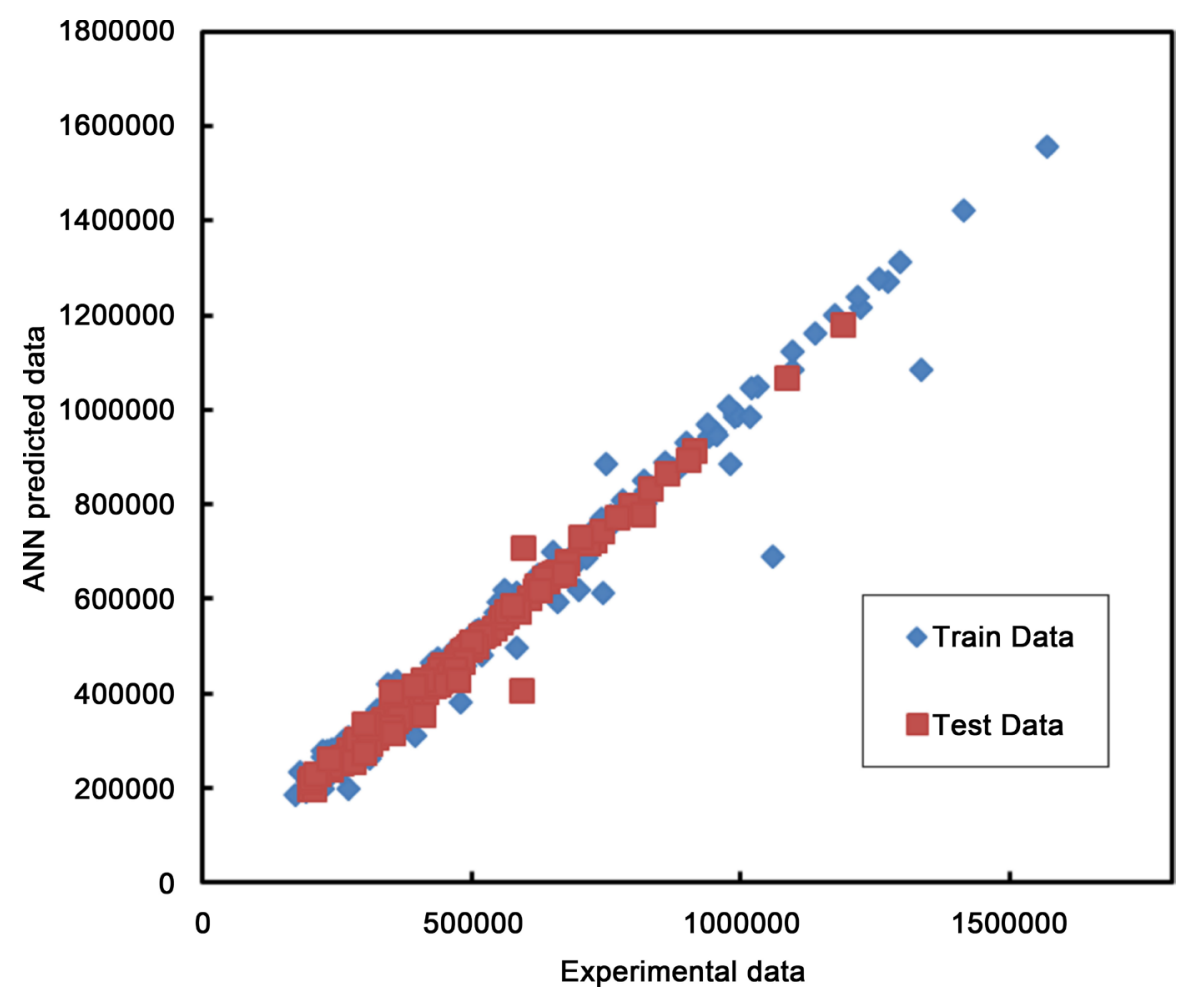

Figure 5. Comparing of the experimental data and predicted results of network.

bins is shown in Figure 6. According to the Figure 6, it can be seen that the histogram has a peak around 0.017 . Table 3 reports the errors for training and test stages of the ANN model. The weight and biases of this network were reported in Table 4 in order to predict resulted data, and also use this model for finding directly the precise amount of activity coefficients of other materials without carrying out time consuming experiments and using thermodynamic modeling.

In this work, having calculated the activity coefficients at infinite dilution in three different ways, a comparison between their final results has been drawn. 


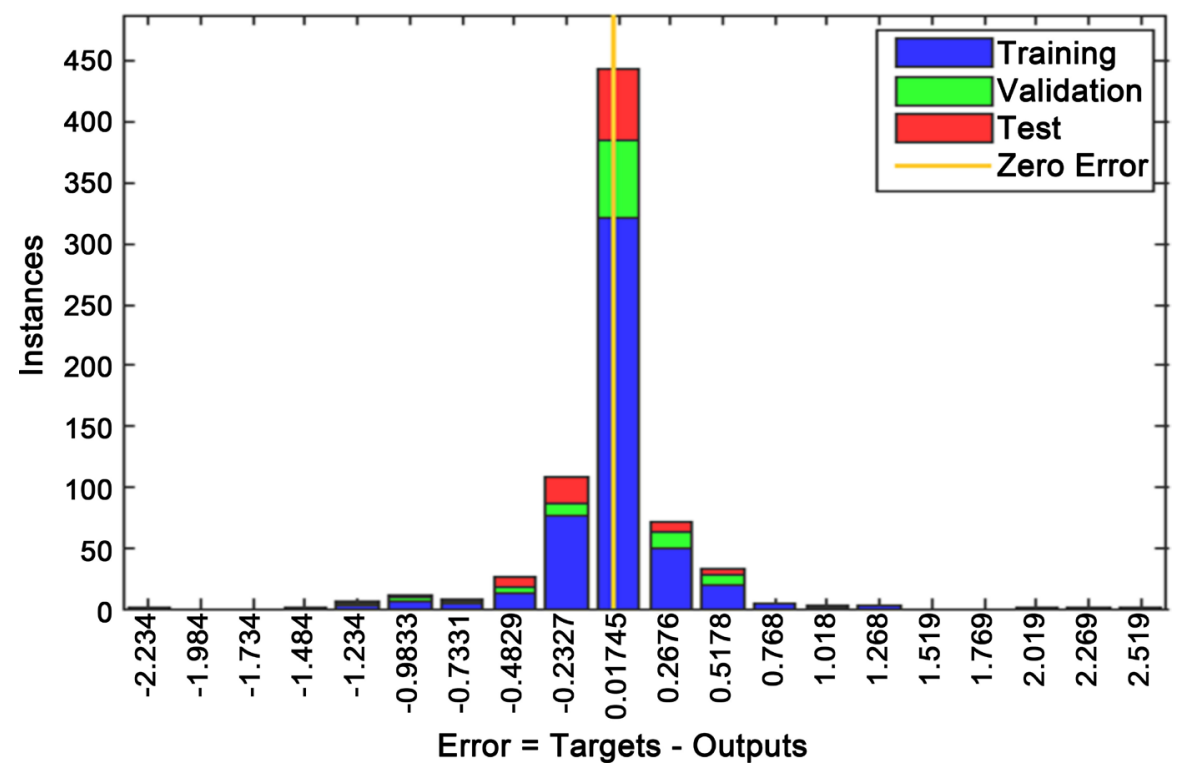

Figure 6. Error histogram with 20 bins obtained using the presented model and number of pure compounds in each range.

Table 3. Statistical properties of trained ANN.

\begin{tabular}{cccc}
\hline Data & Number & average relative error percent & $\mathrm{R}$ \\
\hline Train & 102 & 0.0873 & 0.994 \\
Validate & 21 & 0.1676 & 0.988 \\
Test & 21 & 0.1676 & 0.988 \\
Overall & 144 & 0.1116 & 0.993 \\
\hline
\end{tabular}

Table 4. Weights and Biases of the selected artificial neural network.

\begin{tabular}{cccccccc}
\hline \multirow{2}{*}{$\begin{array}{c}\text { Hidden layer } \\
\text { neuron }\end{array}$} & 1 & 2 & 3 & 4 & 5 & 6 & 7 \\
\cline { 2 - 8 } & 0.84599 & -0.64791 & 0.041857 & -6.46673 & -0.74503 & 0.065056 & -0.00501 \\
Vsat & -0.43605 & -0.60363 & -0.67509 & 1.42567 & -2.02872 & -0.56282 & -1.36424 \\
Psat & -0.62664 & 3.026805 & 1.83053 & 4.555867 & 8.531572 & 2.544383 & 3.790702 \\
t' & -0.20605 & 0.29563 & 0.279518 & 0.150291 & 1.031618 & 0.327164 & 0.489746 \\
J & 1.07002 & -1.57239 & -0.27529 & -8.62001 & -1.16475 & 0.018138 & -0.37616 \\
$\Gamma$ & & \multicolumn{7}{c}{ Optimal neural network Biases } \\
\hline & 6.290099 & -2.47087 & -0.35334 & 0.533857 & -0.31865 & 3.139325 & -0.59779 \\
\hline Bias & &
\end{tabular}

The first method is based on using experimental data extracted from the thermodynamic model. In the second method, data were obtained from ANN model and the third method is based on the thermodynamic model used ANN predicted data. Table 5 presents the results achieved through these methods. In this comparison, the first method that used experimental data for calculating activity coefficient is chosen as the basis to calculate errors. As it is shown in Table 5, that predicted activity coefficient extracted from ANN model has the smallest error. The Average Overall error of test data for the second and third method is 
Table 5. Comparison between activity coefficient of the test data that calculated with three different method; Using thermodynamic model that used experimental data; ANN output; Using thermodynamic model that used ANN prediction data.

\begin{tabular}{|c|c|c|c|c|}
\hline \multirow[b]{2}{*}{$\begin{array}{c}\text { Calculated test } \\
\text { data using } \\
\text { thermodynamic model }\end{array}$} & \multicolumn{4}{|c|}{ Output } \\
\hline & $\begin{array}{l}\text { Predicted gama } \\
\text { using ANN }\end{array}$ & $\begin{array}{c}\text { calculated } \\
\text { by ANN data }\end{array}$ & $\begin{array}{l}\text { error of the } \\
\text { ANN } \\
\text { predictions }\end{array}$ & $\begin{array}{c}\text { error of the thermodynamic } \\
\text { predictions by use of ANN } \\
\text { outputs }\end{array}$ \\
\hline 0.302 & 0.23 & 0.4615 & 0.072 & 0.1595 \\
\hline 2.3168 & 2.587 & 3.5023 & 0.2702 & 1.1855 \\
\hline 0.3726 & 0.5664 & 0.3205 & 0.1938 & 0.0521 \\
\hline 5.357 & 5.60408 & 12.638 & 0.24708 & 7.281 \\
\hline 0.2362 & 0.2451 & 0.2613 & 0.0089 & 0.0251 \\
\hline 0.4863 & 0.6772 & 1.079 & 0.1909 & 0.5927 \\
\hline 0.5237 & 0.6686 & 0.3 & 0.1449 & 0.2237 \\
\hline 0.4219 & 0.21254 & 0.70601 & 0.20936 & 0.28411 \\
\hline 0.4311 & 0.351215 & 0.4143 & 0.079885 & 0.0168 \\
\hline 2.7947 & 2.8557 & 9.1918 & 0.061 & 6.3971 \\
\hline 0.4306 & 0.98219 & 0.40056 & 0.55159 & 0.03004 \\
\hline 5.5809 & 6.06188 & 7.2775 & 0.48098 & 1.6966 \\
\hline 5.8924 & 6.3578 & 7.92725 & 0.4654 & 2.03485 \\
\hline 0.6637 & 0.6582 & 0.42118 & 0.0055 & 0.24252 \\
\hline 0.4967 & 0.55293 & 0.36778 & 0.05623 & 0.12892 \\
\hline 0.6564 & 0.836017 & 0.26141 & 0.179617 & 0.39499 \\
\hline 2.3271 & 2.7655 & 0.8657 & 0.4384 & 1.4614 \\
\hline 0.3704 & 0.515176 & 0.67011 & 0.144776 & 0.29971 \\
\hline 7.6835 & 6.57 & 1.82817 & 1.1135 & 5.85533 \\
\hline 0.17117 & 0.27 & 0.18824 & 0.0988 & 0.0818 \\
\hline 0.24652 & 0.1968 & 0.28503 & 0.04972 & 0.03851 \\
\hline \multicolumn{3}{|c|}{ Average Overall error of test data } & 0.24113 & 1.353213 \\
\hline
\end{tabular}

0.24 and 1.35 , respectively.

\section{Discussion}

The chromatographic data has been used in order to determine the values of activity coefficients at infinite dilution by either thermodynamic or ANN model. In the thermodynamic model, the values of activity coefficients at infinite dilution have been calculated for 12 solutes at different temperatures $(308,313,318$ and $323 \mathrm{~K})$ in three columns with different stationary phase loadings $(10 \%, 15 \%$ and $20 \%$ ). It can be seen that the results obtained from two models come from a broadly similar direction. As a result, ANN can be efficiently used to measure the values of activity coefficients at infinite dilution in different temperatures. A great advantage associated with ANN model is that the values of activity coefficients at infinite dilution can be directly obtained through retention time $\left(t_{r}\right)$, the saturated liquid molar volume $\left(V^{*}\right)$, the probe vapor pressure $\left(P^{s}\right)$ and the ioni- 
zation energy $(I)$ at $T$, without getting involved in complicated thermodynamic computations. According to the strong similarity between the results of two models, the range of solutes can be expanded, and the values of activity coefficients at infinite dilution can be predicted precisely by ANN model for an extensive range of solutes according to their retention time $\left(t_{r}\right)$, the saturated liquid molar volume $\left(V^{*}\right)$, the probe vapor pressure $\left(P^{s}\right)$ and the ionization energy $(I)$ at the wanted temperature ( $T)$. As in ANN model all the steps related to the calculation of physiochemical parameters can be skipped, ANN model can be considered as a time-saving and cost-efficient technique for determination of activity coefficients at infinite dilution, in comparison with the thermodynamic model. As it can be seen in Table 1, the Train error in ANN model is 0.087; Validate error is 0.167 ; Test error is 0.166 and the overall error is 0.111 .

\section{References}

[1] Heintz, A., Kulikov, D.V. and Verevkin, S.P. (2001) Thermodynamic Properties of Mixtures Containing Ionic Liquids. 1. Activity Coefficients at Infinite Dilution of Alkanes, Alkenes, and Alkylbenzenes in 4-Methyl-n-Butylpyridinium Tetrafluoroborate Using Gas- Liquid Chromatography, Journal of Chemical \& Engineering Data, 46 1526-1529. https://doi.org/10.1021/je0101348

[2] Heintz, A., Kulikov, D.V. and Verevkin, S.P. (2002) Thermodynamic Properties of Mixtures Containing Ionic Liquids. 2. Activity Coefficients at Infinite Dilution of Hydrocarbons and Polar Solutes in 1-Methyl-3-Ethyl-Imidazolium bis (Trifluoromethyl-Sulfonyl) Amide and in 1, 2-Dimethyl-3-Ethyl-Imidazolium bis (Trifluoromethyl-Sulfonyl) Amide Using Gas-Liquid Chromatography. Journal of Chemical \& Engineering Data, 47, 894-899. https://doi.org/10.1021/je0103115

[3] Heintz, A., Kulikov, D.V. and Verevkin, S.P. (2002) Thermodynamic Properties of Mixtures containing ionic liquids. Activity coefficients at Infinite Dilution of Polar Solutes in 4-Methyl-N-Butyl-Pyridinium Tetrafluoroborate Using Gas-Liquid Chromatography. The Journal of Chemical Thermodynamics, 34, 1341-1347. https://doi.org/10.1006/jcht.2002.0961

[4] Cruickshank, A., Windsor, M. and Young, C. (1966) The Use of Gas-Liquid Chromatography to Determine Activity Coefficients and Second Virial Coefficients of Mixtures. I. Theory and Verification of Method of Data Analysis. Proceedings of the Royal Society of London A: Mathematical, Physical and Engineering Sciences, The Royal Society, 259-270.

[5] Dohnal, V. and Horáková, I. (1991) A New Variant of the Rayleigh Distillation Method for the Determination of Limiting Activity Coefficients. Fluid Phase Equilibria, 68, 173-185. https://doi.org/10.1016/0378-3812(91)85016-N

[6] Lerol, J.-C., Masson, J.-C., Renon, H., Fabries, J.-F. and Sannier, H. (1977) Accurate Measurement of Activity Coefficient at Infinite Dilution by Inert Gas Stripping and Gas Chromatography. Industrial \& Engineering Chemistry Process Design and Development, 16, 139-144. https://doi.org/10.1021/i260061a609

[7] Belting, P.C., Rarey, J., Gmehling, J., Ceriani, R., Chiavone-Filho, O. and Meirelles, A.J. (2014) Measurements of Activity Coefficients at Infinite Dilution in Vegetable Oils and Capric Acid Using the Dilutor Technique. Fluid Phase Equilibria, 361, 215-222. https://doi.org/10.1016/j.fluid.2013.10.035

[8] Eckert, C., Newman, B., Nicolaides, G. and Long, T. (1981) Measurement and Ap- 
plication of Limiting Activity Coefficients. AIChE Journal, 27, 33-40. https://doi.org/10.1002/aic.690270107

[9] Anand, S.C., Grolier, J.P.E., Kiyohara, O., Halpin, C.J. and Benson, G.C. (1975) Thermodynamic Properties of Some Cycloalkane-Cycloalkanol Systems at 298.15K. III. Journal of Chemical \& Engineering Data, 20, 184-189. https://doi.org/10.1021/je60065a020

[10] Trampe, D.B. and Eckert, C.A. (1993) A Dew Point Technique for Limiting Activity Coefficients in Nonionic Solutions. AIChE Journal, 39, 1045-1050. https://doi.org/10.1002/aic.690390613

[11] Harrington, P. (1993) Transfer Functions in Artificial Neural Networks, Center for Intelligent Chemical Instrument. Department of Chemistry, Ohio University, Athens, $\mathrm{OH}$.

[12] Werbos, P. (1974) Beyond Regression: New Tools for Prediction and Analysis in the Behavioral Sciences. PhD Thesis, Harvard University, Cambridge.

[13] Turan, N.G., Mesci, B. and Ozgonenel, O. (2011) Artificial Neural Network (ANN) Approach for Modeling Zn (II) Adsorption from Leachate Using a New Biosorbent. Chemical Engineering Journal, 173, 98-105. https://doi.org/10.1016/j.cej.2011.07.042

[14] Astray, G., Morales, J., González-Temes, M., Mejuto, J.C. and Magdalena, A.J. (2015) Alternative Method to Predict Activity Coefficients at Infinite Dilution of Hydrocarbons in Aqueous Solutions. Mediterranean Journal of Chemistry, 3, 1073-1082. https://doi.org/10.13171/mjc.3.6.2015.01.02.11.25.astray

[15] Behrooz, H.A. and Boozarjomehry, R.B. (2017) Prediction of Limiting Activity Coefficients for Binary Vapor-Liquid Equilibrium Using Neural Networks. Fluid Phase Equilibria, 433, 174-183. https://doi.org/10.1016/j.fluid.2016.10.033

[16] Everett, D. (1965) Effect of Gas Imperfection on GLC Measurements: A Refined Method for Determining Activity Coefficients and Second Virial Coefficients. Transactions of the Faraday Society, 61, 1637-1645. https://doi.org/10.1039/tf9656101637

[17] Cruickshank, A., Gainey, B., Hicks, C., Letcher, T., Moody, R. and Young, C. (1969) Gas-Liquid Chromatographic Determination of Cross-Term Second Virial Coefficients using Glycerol. Benzene + Nitrogen and Benzene + Carbon Dioxide at $50 \mathrm{C}$. Transactions of the Faraday Society, 65, 1014-1031. https://doi.org/10.1039/TF9696501014

[18] Riddick, J.A., Bunger, W.B. and Sakano, T.K. (1986) Organic Solvents: Physical Properties and Methods of Purification. 4th Edition, Wiley Interscience, Hoboken.

[19] TRC (1990) Thermodynamic Tables. Thermodynamics Research Centre, The Texas A\&M University System College Station, College Station.

[20] McGlashan, M.L. and Potter, D.J.B. (1951) An Apparatus for the Measurement of the Second Virial Coefficient using Glycerol. Proceedings of the Royal Society, 267, 448-456.

[21] Reid, R.C., Prausnitz, J.M. and Sherwood, T.K. (1977) The Properties of Gases and Liquids. 3rd Edition, Chem. Eng. Series, McGraw-Hill, New York.

[22] Prausnitz, J.M., Lichtenthaler, R.N. and Azevedo, E.G. (1986) Molecular Thermodynamics of Fluid Phase Eqilibria. 2nd Edition, Prentice Hall, New York.

[23] Hudson, G.H. and McCoubrey, J.C. (1960) Intermolecular Forces between Unlike Molecules. A More Complete Form of the Combining Rules. Transactions of the Faraday Society, 56, 761-766. https://doi.org/10.1039/tf9605600761 
[24] Arriagada, J., Olausson, P. and Selimovic, A. (2002) Artificial Neural Network Simulator for SOFC Performance Prediction. Journal of Power Sources, 112, 54-60. https://doi.org/10.1016/S0378-7753(02)00314-2

[25] Boccaletti, C., Cerri, G. and Seyedan, B. (2000) A Neural Network Simulator of a Gas Turbine with a Waste Heat Recovery Section. Journal of Engineering for Gas Turbines and Power, 123, 371-376.

[26] Fast, M., Assadi, M. and De, S. (2009) Development and Multi-Utility of an ANN Model for an Industrial Gas Turbine. Applied Energy, 86, 9-17. https://doi.org/10.1016/j.apenergy.2008.03.018

[27] Sadrzadeh, M., Mohammadi, T., Ivakpour, J. and Kasiri, N. (2009) Neural Network Modeling of $\mathrm{Pb}^{2+}$ Removal from Wastewater using Electrodialysis. Chemical Engineering and Processing: Process Intensification, 48, 1371-1381.

https://doi.org/10.1016/j.cep.2009.07.001

[28] Messikh, N., Bousba, S. and Bougdah, N. (2017) The Use of a Multilayer Perceptron (MLP) for Modelling the Phenol Removal by Emulsion Liquid Membrane. Journal of Environmental Chemical Engineering, 5, 3483-3489.

[29] Shekofteh, Y., Almasganj, F. and Daliri, A. (2015) MLP-Based Isolated Phoneme Classification using Likelihood Features Extracted from Reconstructed Phase Space. Engineering Applications of Artificial Intelligence, 44, 1-9. https://doi.org/10.1016/j.engappai.2015.05.001

[30] Cybenko, G. (1989) Approximation by Superpositions of a Sigmoidal Function. Mathematics of Control, Signals, and Systems (MCSS), 2, 303-314. https://doi.org/10.1007/BF02551274

[31] Huang, G.-B., Chen, Y.-Q. and Babri, H.A. (2000) Classification Ability of Single Hidden Layer Feedforward Neural Networks. IEEE Transactions on Neural Networks, 11, 799-801. https://doi.org/10.1109/72.846750

[32] Kianpour, M., Sobati, M.A. and Shahhosseini, S. (2012) Experimental and Modeling of $\mathrm{CO}_{2}$ Capture by Dry Sodium Hydroxide Carbonation. Chemical Engineering Research and Design, 90, 2041-2050. https://doi.org/10.1016/j.cherd.2012.04.005

[33] Tirandazi, B., Yahyaee, A., Kianpour, M. and Shahhosseini, S. (2017) Experimental Investigation and Modeling of Viscosity Effect on Carbon Dioxide Absorption using Sodium Hydroxide. Journal of Environmental Chemical Engineering, 5, 2597-2604.

[34] Hush, D.R. and Horne, B.G. (1993) Progress in Supervised Neural Networks. IEEE Signal Processing Magazine, 10, 8-39. https://doi.org/10.1109/79.180705

[35] Farshad, F., Iravaninia, M., Kasiri, N., Mohammadi, T. and Ivakpour, J. (2011) Separation of Toluene/n-Heptane Mixtures Experimental, Modeling and Optimization. Chemical Engineering Journal, 173, 11-18. 


\section{Nomenclature}

\begin{tabular}{|c|c|c|}
\hline $\bar{\alpha}$ & mean amount of the data & Equation (6) \\
\hline$\alpha_{i}$ & network output & Equation (6) \\
\hline$B^{11}$ & the second virial coefficient & Equation (1) \\
\hline$B^{12}$ & the mutual virial coefficient & Equation (1) \\
\hline$\gamma_{i}^{\infty}$ & activity coefficient at infinite dilution & Equation (1) \\
\hline$e_{i}$ & the differences between experimental and predicted data & Equation (4) \\
\hline$J$ & correction factor & Equations (1)-(3) \\
\hline$N$ & mole number of the stationary phase component inside the column & Equation (1) \\
\hline$n_{0}$ & number of outputs & Equation (5) \\
\hline$n_{t o t}$ & total number of network parameters & Equation (5) \\
\hline$n_{h i}$ & number of the neurons in the $i$ th hidden layer & Equation (5) \\
\hline$P$. & outlet pressure & Equations ((1), (3)) \\
\hline$P_{i}$ & inlet pressure & Equation (3) \\
\hline$P^{\varepsilon}$ & probe vapor pressure & Equation (1) \\
\hline$R$ & ideal gas constant & Equation (1) \\
\hline$R$ & correlation coefficient & Table 3 \\
\hline$T$ & Temperature & Equation (1) \\
\hline$T_{c}^{11}$ & critical temperature & Equation (1) \\
\hline$T_{c}^{12}$ & mutual critical temperature & Equation (1) \\
\hline$t_{r}^{\prime}$ & adjusted retention time & Equation (2) \\
\hline$\tau_{i}$ & the target & Equation (6) \\
\hline $\bar{\tau}$ & mean amount of the data & Equation (6) \\
\hline$U_{0}$ & flow rate of carrier gas & Equation (2) \\
\hline$V^{N}$ & standardized retention volume & Equations ((1), (2)) \\
\hline$V^{*}$ & molar volume of solute & Equation (1) \\
\hline$V^{\infty}$ & partial molar volumes of the solutes at infinite dilution & Equation (1) \\
\hline$V_{c}^{11}$ & critical volume & Equation (1) \\
\hline$V_{c}^{12}$ & mutual critical volume & Equation (1) \\
\hline
\end{tabular}

